\title{
Comparison Study on Prevalence of Psychological Maltreatment and Its Relationship with Psychological Stress and Self-Esteem among School Students in Tanzania and China
}

\author{
Adela A. Mwakanyamale*, Mathew D. Ndomondo \\ Department of Medical and Surgical Nursing, Faculty of Nursing, Hubert Kairuki Memorial University, Dar es Salaam, Tanzania \\ Email: ^ademwaka@yahoo.com, Mathew.ndomondo@bn.hkmu.ac.tz
}

How to cite this paper: Mwakanyamale, A.A. and Ndomondo, M.D. (2019) Comparison Study on Prevalence of Psychological Maltreatment and Its Relationship with Psychological Stress and Self-Esteem among School Students in Tanzania and China. Open Journal of Nursing, 9, 724-741. https://doi.org/10.4236/ojn.2019.97055

Received: May 15, 2019

Accepted: July 23, 2019

Published: July 26, 2019

Copyright $\odot 2019$ by author(s) and Scientific Research Publishing Inc. This work is licensed under the Creative Commons Attribution International License (CC BY 4.0).

http://creativecommons.org/licenses/by/4.0/

\begin{abstract}
Background: Childhood psychological maltreatment in the country paralyses children personal career integration, national development and achievement of plans laid in a given country. In most of the time, psychological maltreatment is masked within other form of child abuse and neglect when they co exit. Knowing the prevalence of childhood psychological maltreatment and the impact associated with trauma of psychological maltreatment synergize the existing evidence-based interventions that are applied to prevent psychological maltreatment. If it is left unattended childhood psychological maltreatment might lead to mental and psychological problems. This study investigates psychological maltreatment: prevalence and its relationship with psychological stress and self-esteem among school students in Tanzania and China. Methods: Participants were selected by multistage cluster sampling respectively in China and Tanzania. In China, participants were recruited randomly from four middle schools in two cities, Xiaogan and Ezhou. In Tanzania, participants were recruited randomly from seven secondary schools in five regions, Kilimanjaro, Tanga, Iringa, Mtwara and Dar es Salaam. Adverse Childhood Experience questionnaire (ACE), Rosenberg self-esteem scale, and Kessler psychological distress scale (K10) were used to gather data. Results: The sample consisted of 555 (55.5\%) female and $445(45.5 \%)$ male $(\mathrm{N}=1000)$ of Tanzanian school students, On the other hand in China the sample size was 3193. Female students were $1650(51.7 \%)$ as compared to male 1543 (48.3\%). The average self-esteem score of student in Tanzania was $(26.14 \% \pm$ 7.45 std deviation) and in China was (22.12 \pm 4.734 std deviation), in Tanzania male have higher 392 (55.3\%) self-esteem scores as compared female 317
\end{abstract}


(44.7), while in China results showed that female have higher self-esteem $1223(50.2 \%)$ than male 1211 (49.8\%). There was a strong positive correlation between psychological maltreatment and self-esteem $(r=0.55, p<0.001)$, whereas the correlation between psychological maltreatment and psychological distress was significantly but weak $(r=-0.086, p=0.007)$. Conclusion: Psychological maltreatment is prevalent in our setting and statistically significant positively affected self-esteem among Tanzanian and China adolescents and is associated with high levels of psychological distress during adolescence. Moreover, exposure to psychological maltreatment during childhood was found to be associated with an increased likelihood of experiencing psychological distress in adolescence. Urgent preventive measures aiming at reducing the incidence of childhood psychological maltreatment is necessary to lessen the incidence of low self-esteem and psychological distress among Tanzanian and China adolescents.

\section{Keywords}

Psychological Maltreatment, Childhood Experience, Self-Esteem, Psychological Distress, Tanzania, China

\section{Background}

Psychological maltreatment has no specific definition; it has been defined differently by different authors and in most of the articles has been used interchangeably as either psychological maltreatment or emotional maltreatment. Psychological maltreatment as a condition occurs when there are acts of omission or commission causing harm or pain on the child's well-being, and this may be reflected as emotional distress or abnormal behavior to the child [1]. The omission and commission acts may occur one at once or both. These actions include isolating, spurning, exploiting, terrorizing and denying emotional responsiveness on the child [2]. Also, it can refer to a repeated pattern of behaviors that express to children that they are worthless, unwanted, unloved, or only of value in meeting parent's/guardian's or another's needs; this leads to lasting damage to their well-being and development [3].

The problem of psychological maltreatment is not limited to the Africa but relatively occurs all over the world. Around the world the prevalence of psychological child maltreatment is approximated to be $36 \%$ [4]. According to previous studies, the rate of psychological children maltreatment was $11 \%$ in the USA, 23\% in England, 23\% in Canada, and 34\% in Australia [5]. The rate was demonstrated to be slightly higher in East Asia and the Pacific Region for $31.3 \%$ and 68.5\% for Korea and China respectively [6].

Childhood psychological maltreatment in the country paralyses children personal career integration, national development and achievement of plans laid in a given country [7]. In most of the time, psychological maltreatment is masked within other form of child abuse and neglect when they co exit [7]. In Tanzania 
studies showed that orphan is at increased risk of experiencing neglect [8]. The effort towards reduction of HIV prevalence and mental illnesses like psychological trauma, anxiety, chronic depression and post-traumatic stress disorder will not be successful unless children are raised in safe environments at home, school and other socialization areas where they are nurtured. Knowing the prevalence of maltreatment and the impact associated with trauma of psychological maltreatment synergize the existing evidence-based interventions that are applied to prevent psychological maltreatment. If it is left unattended childhood psychological maltreatment might lead to mental and psychological problems [9]. Other studies have demonstrated that maltreatment affects the overall school performance, social relationship and peer interaction. Some other study has linked the severity of psychological maltreatment with emotional abuse and intellectual functioning [2].

Very limited comprehensive studies which have looked at the multiple forms of psychological maltreatment in China, and it has been reported that psychological maltreatment on children is associated with psychological distress, maladaptive behavior and is linked with economic decline [7]. Psychological maltreatment can generally be associated with several factors in the environment where a child is either grown or ever experienced at one or more times; these factors are like family interaction/behavior, school interaction, social community, socioeconomic status, guardian demographic [9]. The negative interaction in any of the mentioned arena might result into a psychological trauma to a child. The long-standing trauma associated with characteristics and behaviors such as reduced school performance, negative self-esteem, suicidal behavior, drug abuse and some more other forms of mental disorders [10]. Childhood psychological maltreatment affects individual child intellectual function and might also inflict pains to the family structure functioning and entangle the burden to the society outside those family members.

Worldwide, researchers have demonstrated that exposure to maltreatments throughout childhood and adolescence can lead to escalation of susceptibility to a wide-range of disorders ranging from disorders to mental illness and physical health problems, such as depression, unwanted pregnancy and sexually transmitted diseases, including human immune deficiency virus (HIV) [11].

Children who have experienced abuse often have higher lifelong prevalence of suicidal ideation and disability than the general population. It has also been found that children who have been emotionally abused or neglected suffer impairments of their health and development. However, there may be explanations for this other than emotional abuse and neglect during the starting point of impairment in the child's functioning.

Despite the fact that many studies have focused on psychological maltreatment in childhood, there is an insufficiency of published data that define early childhood experience of psychological maltreatment and its relationship with self-esteem and psychological stress among adolescence in Tanzania and China. This knowledge gap prompted the author to conduct this study in both settings. 
This study aimed to examine early childhood experience of psychological maltreatment and its relationship with psychological stress and self-esteem among students in Tanzania and China.

\section{Methods}

\subsection{Study Design}

This was a cross-sectional, community-based study of school students.

\subsection{Study Area}

This study covered two countries; Tanzania and China randomly selected schools in Tanzania and China from April 2017 to February 2018.

\subsection{Study Participants}

The participants of this study were randomly selected from school students from schools in both Tanzania and China. The study involved one thousand (1000) respondents in Tanzania. This consists of five hundred fifty-three (55.3\%) male students and another 447 (44.7\%) female students. On the other hand, in China the sample size was 3193 female students were 1650 (51.7\%) as compared to male 1543 (48.3\%).

As there were no previous studies in Tanzania and China regarding psychological maltreatment: prevalence and its relationship with psychological stress and self-esteem among school students in Tanzania and China, we could not calculate the sample size based on prevalence. Consequently, a convenience sample size of 1000 students for Tanzania and 3193 for China (including both genders) was selected for the study.

\subsection{Data Collection Method and Tool Used}

The instruments that were used are three different questionnaires to measure the variables under the study. The questionnaire had items from three main following instruments: Rosenberg self-esteem scale, Kessler psychological distress scale (K10) and the Adverse Childhood Experience (ACE) questionnaire.

1) The Rosenberg Self-Esteem Scale: This is a Likert scale developed by Dr. Morris Rosenberg. It consists of ten items, and it is used globally to assess adolescent's self-concept (Self-esteem), i.e., positive and negative feelings about oneself. It has been validated cross-culture and is an important tool, which is used in international surveys of World Health Organization (WHO) [12]. The instrument has excellent psychometric features and is used in assessing the link between child maltreatment and psychological adjustment [13].

The scale measures state self-esteem. Based on this respondent are asked to reflect on their current feelings. In the scale, there are five positively and five negatively worded statements. The items are rated on a 4-point scale from 1, which is strongly agree, to 4 -which is strongly disagree, and the final score is determined as a total of all the ratings. The score ranges from 0 and maximum 
40, with 40 being the highest score (each item ranges from a scores of 1 to 4 ). The higher the student's score, the higher level of self-esteem will be. Basically, the score between 15 and 20 is observed to be normal; and score $<15$ is considered to indicate low self-esteem, while score $>25$ is considered to indicate high self-esteem. There is a high level of reliability and validity on the scale for measuring global self-esteem [14].

Significantly, global self-esteem with test-retest correlations value between 0.82 and 0.88 is measured by a high level of reliability and validity [15]. The Cronbach's alpha of the scale in the present study was 0.83 .

2) Adverse Childhood Experience (ACE) questionnaires were used in the assessment of the emotional abuse and emotional neglect (psychological maltreatment). ACE is made up of 38 items which assess the exposure to 10 types of ACEs based on abuse, neglect and household challenges. These subcategories of abuse, neglect and household challenges include emotional, physical, and sexual abuse for abuse; physical and emotional neglect, and the last being mental illness, substance abuse, and physical violence as household challenges.

In the Adverse Childhood Experience (ACE) questionnaire, a measure of Psychological maltreatment was provided by emotional abuse and neglect scales. These scales consisted of a sum of 7 items, 5 of were used to measure emotional neglect, and 2 items measured emotional abuse. In fact, Childhood Trauma Questionnaire (CTQ) was used to derive items for measuring emotional neglect. CTQ is a measurement tool that demonstrates good reliability and validity among university students [16]. In the international settings, the measures of emotional abuse have demonstrated reliability and validity, due to that, they are highly used by the Centre for Disease Control [17].

In determining an individual's ACE score (range: 0 - 10), one point is given for exposure to each of the different categories (i.e., sexual abuse, emotional neglect, or family members with mental health issues, etc.). For example, an ACE score of 0 reflects no exposure to any of the categories of maltreatment, while an ACE score of 10 reflects exposure to all of the maltreatment categories. The frequency of abuse/maltreatment was not counted into the ACE score.

3) The Kessler Psychological Distress scale (K10) it is globally used to measure non-specific psychological distress in the anxiety depression spectrum. It was developed by Professors Kessler and Mroczek in 1992-. The K10 consists of 10 questions about psychological distress. Again, it is designed to quantify the frequency and severity of anxiety. Not only that, it is also used to quantify depression-related symptoms experienced during the four weeks before screening. This scale has been validated cross-culture and is a fundamental instrument for international surveys of World Health Organization (WHO). In this scale, an increased likelihood of a psychological disorder is indicated by high scores on the scale, [18].

During data collection process, respondents were asked the question: "How often did you feel: 1) tired out for no good reason; 2) nervous; 3) so nervous that nothing could calm you down; 4) hopeless; 5) restless or fidgety; 6) so restless 
you could not sit still; 7) sad or depressed; 8) so depressed that nothing could cheer you up; 9) everything was an effort; 10) worthless, during the past month?" Each of the ten items in the question was scored from 1 to 5 on a Likert-type scale.

Items were rated on a five-point ordinal scale. All of the time was indicated by score 5 , most of the time, it was score 4), some of the time was score 3, a little of the time was score 3 , and none of the time was indicated by score 1 . The total K10 score for each respondent was realized as a total of all 10 items. The scores ranged from 10 to 50 .

The score under 20 was considered normal meaning that there is no stress, score 20 - 24 indicated mild mental disorder (mild stress), score 25 - 29 indicated moderate mental disorder (moderate stress), while score 30 and over indicated a severe mental disorder (severe stress).

The developers of the tool do not recommend standardizing scoring, but they recommend scores to be interpreted based on the studied population. Several methods of scoring the K10 have been used in Australia, with the following scoring used by the Victorian Population Health Surveys [19]. The expression of distress in Tanzania it has been suggested to base on cultural norms relating in part to observable differences in rating psychological distress between women and men. However, a recent methodological study on the construct validity of the K6, which is a shortened form of K10 made up of 6 of the original ten items, concludes that the K6 is both a sex- and age-neutral scale [20]. This is to say, any observed differences in K6 scores between women and men or between people at different ages show true differences in psychological distress. Also, the differences are not the result of bias resulting from differences in interpretation or understanding of the K6 questions.

\subsection{Sampling Technique}

A multistage cluster sampling technique was employed to obtain the required number of study participants. A sampling frame from the list of school students from randomly selected schools in both countries was prepared and used to draw up the sample. From the sampling frame, study units were sampled through the simple random method until the required sample was obtained.

\subsection{Study Variables}

In the study there were two variables, independent and dependent variables. Psychological maltreatment was the independent variable, while the dependent variables constitute self-esteem and psychological stress.

\subsection{Quality Assurance and Control}

To ensure quality in this research all techniques, systems and resources were arrayed to give assurance about data collection process, data handling and data analysis. This research translated all questionnaire from its original language English 
to Swahili (Tanzania language) and from its original language English to Chines language for Chinese students so that all students in Tanzania and China understood the questions, questionnaire was submitted to students by a well-trained research assistant the responsibilities of those involved in the field for data collection. Research plan was made known to all research team and data was handling in confidential manner. Researcher read the filled questionnaires and ensure completeness. Soon after collection, data was coded entered in software statistical package for social science (SPSS) and second cleaning were done.

\subsection{Validity and Reliability}

Data collection tools were checked for validity and reliability. In reliability all questionnaires were checked for the extent of yielding the same results on repeated administration of the tool. The Cronbach's alpha was used to check internal consistence coefficient alpha is an internal consistency index designed to be used in tests which contain items which have no right answer.

All tools adopted for data collection. The Rosenberg Self-Esteem Scale and The Kessler Psychological Distress scale Cronbach's Alpha was used to measure the internal consistence of the instrument and construct validity was measured by CFI.

\subsection{Data Analysis and Presentation}

Statistical package for social sciences (SPSS) version 20.0 (SPSS, Chicago IL, USA) for Windows was used in performing statistical data analysis. Descriptive statistics like mean (+Standard deviation) and ranges on one hand were calculated on continuous variables. On the other hand, on categorical variables, proportions and frequency tables were used to summarize the information. Furthermore, the significance of association between the independent (psychological maltreatment) and dependent (self-esteem) variables in the categorical variables was tested by Chi square $\left(\chi^{2}\right)$. Multivariate logistic regression analysis was used to determine whether childhood psychological maltreatment predicts self-esteem during adolescence period, while the level of significance was considered as $\mathrm{p}<$ 0.05 .

\subsection{Ethical Consideration}

All the participants were informed about the purpose of the study and were ensured that their answers would only be used anonymously for research purposes. Thereafter they were asked if they were willing to participate on a voluntary basis. Thus, informed consent was sought from each participant before they were enrolled into the study. Ethical approval to conduct the study was obtained from the Tongji Medical College, Huazhong University of Science and Technology institutional ethic review committee before the commencement of the study. Again, permission to conduct the study in respective schools was also obtained from school authorities. 


\subsection{Study Limitation and Delimitation}

This study covered few students from Tanzania and China. This might bring difficult in generalization of the results. The researcher increased the sample size to foster variability of the subject which might prove the legacy of generalizing results.

\section{Results}

\subsection{Characteristics of the Study Population}

The sample consisted of $555(55.5 \%)$ female and $445(45.5 \%)$ male $(\mathrm{N}=1000)$ of Tanzanian school students, On the other hand in China the sample size was 3193. Female students were 1650 (51.7\%) as compared to male 1543 (48.3\%) (Table 1).

\subsection{Correlation Analysis between Psychological Maltreatment and Gender}

The correlation analysis in Table 2 above shows a strong correlation between psychological maltreatment and gender $(r=0.13, p<0.01)$.

\subsection{Self-Esteem Mean Scores between Tanzania and China}

The average self-esteem score of students in Tanzania was $26.14 \pm 7.45$.

In China was $22.12 \pm 4.734$ (Table 3).

\subsection{Prevalence of Self-Esteem between Tanzania and China by Gender}

As shown in Table 4, in Tanzania, it was shown that most students had high self-esteem 709 (70.9\%) with slightly differences in number and percentage between low self-esteem and normal self-esteem. Males were reflected to have higher $392(55.3 \%)$ self-esteem scores as compared to females 317 (44.7\%) when $\mathrm{P}$-value $=001$. On the contrary, in China the results showed that most students had normal self-esteem 2434 (76.2\%) of which 1223 (50.2\%) reported to be females and 1211 (49.8\%) males. The difference in score between male and female on self-esteem was observed when p-value $=0.001$.

\subsection{Correlation between Self-Esteem and Gender}

Table 5 shows a strong positive correlation between self-esteem and gender $(\mathrm{r}=$ $0.51, \mathrm{p}<0.001)$.

\subsection{Comparison in Average Scores of Students with Psychological Distress between Tanzania and China}

The average score of psychological distress among students in Tanzania was 19.84 with the minimum score being 11 and maximum score 46, while average score of students with psychological stress in china was 25.84 with the minimum score being 10 and maximum score 50 (Table 6). 
Table 1. Socio-demographic characteristics of the study sample.

\begin{tabular}{ccc}
\hline Variables & Tanzania & China \\
\cline { 2 - 3 } Sex & $\mathrm{N}(\%)$ & $\mathrm{N}(\%)$ \\
\hline Male & $445(45.5)$ & $1543(48.3)$ \\
Female & $555(55.5)$ & $1650(51.7)$ \\
Total & $1000(100 \%)$ & $3193(100 \%)$ \\
\hline
\end{tabular}

Table 2. Correlation analysis among students (gender) and psychological maltreatment.

\begin{tabular}{ccc}
\hline Variable & Psychological maltreatment & Gender of the students \\
\hline $\begin{array}{c}\text { Psychological maltreatment } \\
\text { Gender of the students }\end{array}$ & 1 & $0.130^{* *}$ \\
\hline
\end{tabular}

${ }^{* *}$ Correlation is significant at the 0.01 level (2-tailed).

Table 3. Self-esteem mean scores between Tanzania and China.

\begin{tabular}{ccccc}
\hline Countries & Mean & Mode & STD Deviation & N \\
\hline Tanzania & 26.14 & 31 & 7.45 & 1000 \\
China & 22.12 & 20 & 4.734 & 3193 \\
\hline
\end{tabular}

Table 4. Prevalence of self-esteem between Tanzania and China by gender.

\begin{tabular}{|c|c|c|c|c|}
\hline \multirow{2}{*}{ Countries } & \multirow{2}{*}{ Categories N (\%) } & \multicolumn{2}{|c|}{ Sex } & \multirow{2}{*}{$\mathrm{p}-$ Value } \\
\hline & & Male N (\%) & Female N (\%) & \\
\hline \multirow{3}{*}{ Tanzania } & Low self-esteem = $163(19.3)$ & $104(63.8)$ & $59(36.2)$ & \multirow{3}{*}{0.01} \\
\hline & Normal Self-esteem = 118 (12.8) & $59(46.1)$ & $69(53.9)$ & \\
\hline & High self-esteem = 709 (70.9) & $392(55.3)$ & $317(44.7)$ & \\
\hline \multirow{3}{*}{ China } & Low self-esteem $=57(1.8)$ & $17(29.8)$ & $40(70.2)$ & \multirow{3}{*}{0.001} \\
\hline & Normal Self-esteem $=2434(76.2)$ & $1211(49.8)$ & $1223(50.2)$ & \\
\hline & High self-esteem = 702 (22) & $315(44.9)$ & $387(55.1)$ & \\
\hline
\end{tabular}

Table 5. Correlation analysis of self-esteem by gender and age groups.

\begin{tabular}{cccc}
\hline Variables & 1 & 2 & 3 \\
Self-esteem & - & - \\
Age of participants & 0.035 & $-0.195^{* *}$ & - \\
Gender of participants & 0.001 & \\
\hline
\end{tabular}

${ }^{* *}$ Correlation is significant at the 0.01 level (2-tailed).

Table 6. Comparison in average scores of students with psychological distress between Tanzania and China.

\begin{tabular}{ccccccc}
\hline Countries & Mean & Mode & STD Deviation & Min & Max & N \\
\hline Tanzania & 19.84 & 12 & 7.545 & 11 & 46 & 1000 \\
China & 25.84 & 40 & 9.128 & 10 & 50 & 3193 \\
\hline
\end{tabular}




\subsection{Prevalence of Psychological Distress among Tanzanian and Chinese by Gender}

Table 7 below shows high rate of severe psychological distress among female students in Tanzania 71 (54.6\%) than in China 513 (44.1\%). Seventy-one (54.6\%) female students in Tanzania have severe psychological distress than male 59 (45.4\%). However, the difference was not statistically significant and P-value was $=0.072$.

Most 649 (55.9\%) male students in China showed higher score of severe psychological distress than female students 513 (44.1\%). The differences in score between male and female students demonstrated statistical significance with $\mathrm{P}$-value $=$ 0.000 .

Male students 556 (59.4) in China and Tanzania 332 (56) showed high rate of normal psychological distress than female students 380 (40.6) and 261 (44) respectively.

\subsection{Level of Self-Esteem on Students with Psychological Distress among Tanzania and China}

A one-way ANOVA was conducted to compare effect of levels of self-esteem on the psychological distress score among students in Tanzania and China. The psychological distress score was statistically significantly different between different levels of self-esteem among students for both in Tanzania $F(2,997)=$ $13.209 \mathrm{p}$ value $=0.000$ and China $\mathrm{F}(2,3190)=54.476 \mathrm{p}$ value $=0.000($ Table 8$)$.

\subsection{Relationship of Psychological Maltreatment and Psychological Distress in Tanzania and in China}

Childhood psychological maltreatment has negative relationship with adolescents feeling of anxious and depressive symptoms which are known as psychological distress. The correlation analysis of individual variables of psychological maltreatment such as emotional neglect has reflected to be negatively linked to psychological distress, while in China childhood emotional abuse is negatively related to psychological distress. However, the relationship is depicted to be weak in both Tanzania and China (See Table 9 and Table 10).

Table 7. Prevalence of psychological distress among Tanzanian and Chinese by gender.

\begin{tabular}{ccccc}
\hline \multirow{2}{*}{ Countries } & Psychological Distress & \multicolumn{2}{c}{ Sex } & \multirow{2}{*}{ p-Value } \\
\cline { 3 - 4 } & N (\%) & Male N (\%) & Female N (\%) & \\
\hline \multirow{3}{*}{ Tanzania } & Normal & $332(56)$ & $261(44)$ & \\
& Mild & $105(59.3)$ & $72(40.7)$ & \multirow{2}{*}{0.072} \\
& Moderate & $59(59)$ & $41(41)$ & \\
& Severe & $59(45.4)$ & $71(54.6)$ & \\
& Normal & $380(40.6)$ & $556(59.4)$ & \\
& Mild & $304(44.1)$ & $386(55.9)$ & 0.000 \\
& Moderate & $210(51.9)$ & $195(48.1)$ & \\
\hline
\end{tabular}


Table 8. Level of self-esteem on students with psychological distress among Tanzania and China.

\begin{tabular}{ccccccc}
\hline & & Sum of Squares & df & Mean Square & F & p-Value \\
\hline \multirow{2}{*}{ Tanzania } & Between Groups & 1467.887 & 2 & 733.943 & 13.209 & 0.000 \\
& Within Groups & $55,397.217$ & 997 & 55.564 & & \\
\multirow{2}{*}{ China } & Between Groups & 8783.307 & 2 & 4391.653 & 54.476 & 0.000 \\
& Within Groups & $257,166.553$ & 3190 & 80.616 & & \\
\hline
\end{tabular}

Table 9. Relationship of psychological Maltreatment on psychological distress in Tanzania.

\begin{tabular}{ccc}
\hline \multicolumn{2}{c}{ Psychological Maltreatment } & K10_Psychological Distress \\
\hline & Pearson Correlation & $-0.140^{* *}$ \\
Emotional Neglect & P-Value & 0.000 \\
& $\mathrm{~N}$ & 3131 \\
Emotional Abuse & Pearson Correlation & $0.056^{* *}$ \\
& P-value & 0.002 \\
& $\mathrm{~N}$ & 3115 \\
\hline
\end{tabular}

${ }^{*}$ Correlation is significant at the 0.01 level (2-tailed).

Table 10. Relationship between psychological maltreatment and psychological distress in China.

\begin{tabular}{ccc}
\hline \multicolumn{2}{c}{ Psychological Maltreatment } & K10_Psychological Distress \\
\hline & Pearson Correlation & $0.118^{* *}$ \\
Emotional Neglect & P-Value & 0.000 \\
& $\mathrm{~N}$ & 2266 \\
Emotional Abuse & Pearson Correlation & $-0.166^{* *}$ \\
& P-Value & 0.000 \\
& $\mathrm{~N}$ & 2265 \\
\hline
\end{tabular}

\subsection{Correlation between Psychological Maltreatment, Self-Esteem and Psychological Distress}

The findings in Table 11 show a strong positive correlation between psychological maltreatment and self-esteem $(\mathrm{r}=0.55, \mathrm{p}<0.001)$, whereas the correlation between psychological maltreatment and psychological distress was significantly weak $(r=-0.086, p=0.007)$. The results also show a strong positive correlation between psychological distress and self-esteem $(r=0.16, p<0.001)$.

\subsection{Linear Regression Analysis between Psychological Maltreatment, Self-Esteem and Psychological Distress}

A simple linear regression model (Table 12) was calculated to predict self-esteem based on psychological maltreatment; $\mathrm{b}=0.51$, (998) 35.08, $\mathrm{p}<0.001$. A significant regression equation was found $(F(1,998))=359.893, p<0.001$, with $R^{2}$ of 0.265 . 
Table 11. Correlation between psychological maltreatment, self-esteem and psychological distress in Tanzania.

\begin{tabular}{ccccc}
\hline Variables & $\mathrm{M} \pm \mathrm{SD}$ & 1 & 2 & 3 \\
\hline 1) Self-esteem & $27.6 \pm 4.2$ & - & & \\
2) Psychological distress & $24.6 \pm 4.5$ & $0.164^{* *}$ & - & - \\
3) Psychological maltreatment & $10.4 \pm 2.3$ & $0.515^{* *}$ & $-0.086^{* *}$ & - \\
\hline
\end{tabular}

${ }^{* *}$ Correlation is significant at the 0.01 level (2-tailed). ${ }^{* *} \mathrm{p}<0.001 . \mathrm{M}$ : Mean, SD $=$ Std Deviation.

Table 12. Linear regression analysis between psychological maltreatment, self-esteem and psychological distress.

\begin{tabular}{ccccccc}
\hline R Square & Adjusted R Square & Df & F & T & Beta & sig \\
\hline 0.265 & 0.264 & 1998 & 359.893 & 35.083 & 0.515 & 0.000 \\
0.007 & 0.006 & & 7.37 & 41.05 & 0.86 & 0.001 \\
\hline
\end{tabular}

Dependent Variable: Self-esteem Predictors: (Constant), Psychological maltreatment.

Approximately $26 \%$ of the variance in self-esteem can be explained by psychological maltreatment. Moreover, Psychological distress can be predicted based on psychological maltreatment; $\mathrm{b}=-0.86$, (998) 41.05, $\mathrm{p}<0.001$.

A significant regression equation was found $(\mathrm{F}(1,998))=7.36, \mathrm{p}<0.001$, with $\mathrm{R}^{2}$ of 0.007 . This means that $0.6 \%$ of the variance in psychological distress can be explained by psychological maltreatment.

\section{Discussion}

Psychological maltreatment in children represents the most challenging and prevalent form of child abuse and neglect worldwide [21], but until recently, it has received relatively little attention in countries like Tanzania and China.

The prevalence of psychological maltreatment in the present study may be an underestimate because this form of child maltreatment is mostly underreported to authorities for fear of being arrested by the police. Also, psychological maltreatment is often not recognized when other forms of maltreatment, such as physical and sexual abuse, coexist [22]. The prevalence rates of psychological maltreatment may also be underestimated because they capture a wide range of parenting behaviours, and there is little to no consensus across studies as to what phenomena should be included [23]. The researcher adequately understands that, this investigation is the first evaluating the comparison study on prevalence of psychological maltreatment and its relationship with self-esteem and psychological distress found in school students in Tanzania and China.

In Tanzania most students had high self-esteem 709 (70.9\%) a figure which is lower than what was realized by Scott KL at al [24], who revealed that $82 \%$ of the study participants had high self-esteem. Also the result revealed that males have higher 392 (55.3\%) self-esteem scores as compared to females 317 (44.7\%) this finding is in agreement with what has previously been reported by Briere J, and Runtz M [25] male high level of self-esteem $80 \%$ as compare to female $62 \%$. 
The prevalence of low self-esteem was 163 (19.3\%) higher in Tanzanian students than Chinese students $57(1.8 \%)$ a figure which is lower than what was realized by Higgins DJ and McCabe MP [26], who revealed that $62 \%$ of the students had experienced low self-esteem.

The result also revealed high rate of severe psychological distress among female students in Tanzania 71 (54.6\%) than in China 513 (44.1\%). This finding is in agreement with what has previously been reported high rate of severe psychological distress among female students $80 \%$ [27] and [28].

In the study by Benbenishty $\mathrm{R}$ et al. [29], female were found to be the most vulnerable showed higher score of severe psychological distress than male students, which is contrary to this study which showed male students in China had higher score of severe psychological distress 649 (55.9\%) than female students $513(44.1 \%)$. The differences in score between male and female students demonstrated statistical significance with $\mathrm{p}$-value $=0.000$. However, we were not able to establish the reasons for the gender differences.

In this study Male students 556 (59.4) in China and Tanzania 332(56) showed high rate of normal psychological distress than female students 380 (40.6) and 261 (44) respectively. This finding is in agreement with what has previously been reported high rate of normal psychological distress among male students $62 \%$ than female students 52\% [30] [31] [32].

Further to that, exposure to psychological maltreatment is reported to have lifelong consequences on mental health, which persist into adolescence and adulthood [33]. In the present study, psychological maltreatment were adversely connected with low self-esteem and psychological distress. This observation corroborates with other studies that reported similar finding [34].

It is clear that psychological maltreatment adversely brings an effect on personality characteristic of people in their childhood, adolescence and adult lives, and it causes lower self-esteem [35]. Studies on adolescents, show that exposure to psychological maltreatment during childhood results in low self-confidence [36].

In our study the result from both Tanzania and China shows strong correlation between psychological maltreatment and gender $(r=0.13, p<0.01)$ and between self-esteem and gender $(r=0.51, \mathrm{p}<0.001)$.

In our study, exposure to psychological distress score was statistically significantly different between different levels of self-esteem among students for both in Tanzania $F(2,997)=13.209 p$ value $=0.000$ and China $F(2,3190)=54.476 p$ value $=0.000$.

In this study it is reported that childhood psychological maltreatment has negative relationship with adolescents feeling of anxious and depressive symptoms which are known as psychological distress. The correlation analysis of individual variables of psychological maltreatment such as emotional neglect has reflected to be negatively linked to psychological distress, while in China childhood emotional abuse is negatively related to psychological distress. However, the relationship is depicted to be weak in both Tanzania and China.

Report shows a strong positive correlation between psychological maltreat- 
ment and self-esteem $(\mathrm{r}=0.55, \mathrm{p}<0.001)$, whereas the correlation between psychological maltreatment and psychological distress was significantly weak $(r=$ $-0.086, p=0.007)$. The results also show a strong positive correlation between psychological distress and self-esteem $(r=0.16, p<0.001)$.

Poor nurturing environment for the child like poor parenting or poor child relation, notably psychological maltreatment affect negatively child's self-esteem. As it has been demonstrated in this study similar other studies have showed stronger relationship between psychological maltreatment on self-esteem [37].

\section{Conclusions}

This study concludes that there is a negative significant relationship between individual childhood psychological maltreatment, psychological distress and self-esteem. Findings from this study demonstrated that childhood psychological maltreatment exists in our setting and has negatively affected self-esteem among Tanzanian adolescents and is associated with high levels of psychological distress during adolescence. It is argued that urgent preventive measures aiming at reducing the occurrence of childhood psychological maltreatment are necessary to be undertaken to reduce the incidence of low self-esteem and psychological distress among Tanzanian and Chinese students. This can be achieved through education efforts that highlight the negative effects of childhood psychological maltreatment. Also, parents/care givers and teachers need to be educated about the potential negative consequences of psychological maltreatment to raise awareness among them as a means of reducing low self-esteem and psychological distress in Tanzania and China. It is therefore recommended that:

Home and school environmental situations are expected to be an ideal and the best fit for safety for a child growth and development in both physically and psychologically. Situations have proven different that carefully measures are to be undertaken by parents/guardians and other closely related people who come close to the child growing environment. That is so because studies have shown that psychological maltreatment is the interplay of several variables including family environment in which children are brought up, parent-child relationships and methods of bringing up children.

Social organization protecting the child should be aware of the impact caused of psychological maltreatment occur at home and school, they have to properly plan for intervention involving the parents, guardians and other people who come close to children psychological and physical growth.

This study has included parts of Tanzania regions and China a bigger study is recommended to include the wider part of the countries for worthwhile generalization of the results.

\section{Acknowledgements}

The authors are grateful to all who participated in the preparation of this manuscript. The authors acknowledge the help of the students who participated in this 
study and the teachers who delivered and collected questionnaires. The authors also acknowledge the contribution of DrPhillipo L. Chalya for his technical support.

\section{Declarations}

\section{Ethics Approval and Consent to Participate}

All the participants were informed about the purpose of the study and were ensured that their answers would only be used anonymously for research purposes. Thereafter they were asked if they were willing to participate on a voluntary basis.

Thus, informed consent was sought from each participant before they were enrolled into the study. Ethical approval to conduct the study was obtained from the Tongji Medical College, Huazhong University of Science and Technology institutional ethic review committee before the commencement of the study. Again, permission to conduct the study in respective schools was also obtained from school authorities.

\section{Availability of Data and Materials}

The datasets used and/or analyzed during the current study are available from the corresponding author on reasonable request.

\section{Funding}

This study had no sources of funding. Authors met all operational costs.

\section{Authors' Contributions}

AM conceived the study, participated in study design, literature search, data analysis and drafted and submitted the manuscript. MN contributed to manuscript writing and editing. All the authors read and approved the final manuscript.

\section{Conflicts of Interest}

The authors declare that they have no competing interests.

\section{References}

[1] Hibbard, R., Barlow, J., MacMillan, H., et al. (2012) Psychological Maltreatment. Pediatrics, 130, 372-378. https://doi.org/10.1542/peds.2012-1552

[2] Glaser, D. (2002) Emotional Abuse and Neglect (Psychological Maltreatment): A Conceptual Framework. Child Abuse \& Neglect, 26, 697-714. https://doi.org/10.1016/S0145-2134(02)00342-3

[3] Stiefelhagen, P. (2015) How Emotional Abuse Can Cause Illness. MMW Fortschritte Der Medizin, 157, 20. https://doi.org/10.1007/s15006-015-3764-0

[4] Stoltenborgh, M., Bakermans-Kranenburg, M.J., Alink, L.R.A. and van Ijzendoorn, M.H. (2012) The Universality of Childhood Emotional Abuse: A Meta-Analysis of Worldwide Prevalence. Journal of Aggression, Maltreatment \& Trauma, 21, 870-890. 
https://doi.org/10.1080/10926771.2012.708014

[5] Gilbert, R., Widom, C.S., Browne, K., Fergusson, D., Webb, E. and Janson (2009) Burden and Consequences of Child Maltreatment in High-Income Countries. The Lancet, 373, 68-81. https://doi.org/10.1016/S0140-6736(08)61706-7

[6] Trickett, P.K., Mennen, F.E., Kim, K. and Sang, J. (2009) Emotional Abuse in a Sample of Multiply Maltreated, Urban Young Adolescents: Issues of Definition and Identification. Child Abuse and Neglect, 33, 27-35. https://doi.org/10.1016/j.chiabu.2008.12.003

[7] Ward, H. and Brown, R. (2014) Assessing Parental Capacity to Change When Children Are on the Edge of Care: An Overview of Current Research Evidence. Research Report, 1-193.

[8] Hermenau, K., Eggert, I., Landolt, M.A. and Hecker (2015) Neglect and Perceived Stigmatization Impact Psychological Distress of Orphans in Tanzania. European Journal of Psychotraumatology, 6, Article ID: 28617. https://doi.org/10.3402/ejpt.v6.28617

[9] Dong, M., Anda, R.F., Dube, S.R., Giles, W.H. and Felitti, V.J. (2003) The Relationship of Exposure to Childhood Sexual Abuse to Other Forms of Abuse, Neglect, and Household Dysfunction during Childhood. Child Abuse \& Neglect, 27, 625-639. https://doi.org/10.1016/S0145-2134(03)00105-4

[10] Sesar, K., Živčić-Bećirević, I. and Sesar, D. (2008) Multi-Type Maltreatment in Childhood and Psychological Adjustment in Adolescence: Questionnaire Study among Adolescents in Western Herzegovina Canton. Croatian Medical Journal, 49, 243-256. https://doi.org/10.3325/cmj.2008.2.243

[11] Longman-Mills, S., De La Haye, W., Hamilton, H.A., Brands, B., da Gloria Wright, M. and Cumsille, F. (2015) Psychological Maltreatment and Its Relationship with Substance Abuse among University Students in Kingston, Jamaica. Texto \& Contexto-Enfermagem, 24, 63-68. https://doi.org/10.1590/0104-07072015001070014

[12] Arslan, G. (2015) Psychological Maltreatment, Emotional and Behavioral Problems in Adolescents: The Mediating Role of Resilience and Self-Esteem. Child Abuse \& Neglect, 52, 200-209. http://www.ncbi.nlm.nih.gov/pubmed/26518981 https://doi.org/10.1016/j.chiabu.2015.09.010

[13] Ports, K.A., Ford, D.C. and Merrick, M.T. (2015) Adverse Childhood Experiences and Sexual Victimization in Adulthood. Child Abuse \& Neglect, 51, 313-322. https://doi.org/10.1016/j.chiabu.2015.08.017

[14] Daniali, S., Azadbakht, L. and Mostafavi, F. (2013) Relationship between Body Satisfactions with Self-Esteem and Unhealthy Body Weight Management. Journal of Education and Health Promotion, 2, 29. https://doi.org/10.4103/2277-9531.115804

[15] Kessler, R., Barker, P., Colpe, L., Epstein, J., Gfroerer, J., Hiripi, E., et al. (2003) Screening for Serious Mental Illness in the General Population. Archives of General Psychiatry, 60, 184-189. https://doi.org/10.1001/archpsyc.60.2.184

[16] Paivio, S.C. and Cramer, K.M. (2004) Factor Structure and Reliability of the Childhood Trauma Questionnaire in a Canadian Undergraduate Student Sample. Child Abuse \& Neglect, 28, 889-904. https://doi.org/10.1016/j.chiabu.2004.01.011

[17] Centers for Disease Control and Prevention (2012) Adverse Childhood Experiences (ACE) Study. http://www.cdc.gov/ace/questionnaires.htm

[18] Pratt, L. (2007) Characteristics of Adults with Serious Psychological Distress as Measured by the K6 Scale: United States 2001-2004. Advance Data, No. 382, 1-18. https://doi.org/10.1037/e609262007-001

[19] Slade, T., Grove, R. and Burgess, P. (2011) Kessler Psychological Distress Scale: 
Normative Data from the 2007 Australian National Survey of Mental Health and Wellbeing. Australian \& New Zealand Journal of Psychiatry, 45, 308-316. https://doi.org/10.3109/00048674.2010.543653

[20] Drapeau, A., Beaulieu-Prévost, D., Marchand, A., Boyer, R., Préville, M. and Kairouz, S. (2010) A Life-Course and Time Perspective on the Construct Validity of Psychological Distress in Women and Men. Measurement Invariance of the K6 across Gender. BMC Medical Research Methodology, 10, 68. https://doi.org/10.1186/1471-2288-10-68

[21] Karakus, O. (2012) Relation between Childhood Abuse and Self-Esteem in Adolescence. International Journal of Human Sciences, 9, 753-763.

[22] Chinawa, J.M., Aronu, A.E., Chukwu, B.F. and Obu, H.A. (2013) Prevalence and Pattern of Child Abuse and Associated Factors in Four Secondary Institutions in Enugu, Southeast Nigeria. European Journal of Pediatrics, 173, 451-456.

https://doi.org/10.1007/s00431-013-2191-4

[23] Hart, S.N., Binggeli, N.J. and Brassard, M.R. (1998) Evidence for the Effects of Psychological Maltreatment. Journal of Emotional Abuse, 1, 27-58. https://doi.org/10.1300/J135v01n01_03

[24] Scott, K.L., Wolfe, D.A. and Wekerle, C. (2003) Maltreatment and Trauma: Tracking the Connections in Adolescence. Child and Adolescent Psychiatric Clinics of North America, 12, 211-230. https://doi.org/10.1016/S1056-4993(02)00101-3

[25] Briere, J. and Runtz, M. (1990) Differential Adult Symptomatology Associated with Three Types of Child Abuse Histories. Child Abuse \& Neglect, 14, 357-364. https://doi.org/10.1016/0145-2134(90)90007-G

[26] Higgins, D.J. and McCabe, M.P. (2000) Relationships between Different Types of Maltreatment during Childhood and Adjustment in Adulthood. Child Maltreat, 5, 261-272. https://doi.org/10.1177/1077559500005003006

[27] Arata, C.M., Langhinrichsen-Rohling, J., Bowers, D. and O’Brien, N. (2007) Differential Correlates of Multi-Type Maltreatment among Urban Youth. Child Abuse \& Neglect, 31, 393-415. https://doi.org/10.1016/j.chiabu.2006.09.006

[28] Paul, E. and Eckenrode, J. (2015) Childhood Psychological Maltreatment Subtypes and Adolescent Depressive Symptoms. Child Abuse \& Neglect, 47, 38-47. https://doi.org/10.1016/j.chiabu.2015.05.018

[29] Benbenishty, R., Zeira, A. and Astor, R.A. (2002) Children's Reports of Emotional, Physical and Sexual Maltreatment by Educational Staff in Israel. Child Abuse \& Neglect, 26, 763-782. https://doi.org/10.1016/S0145-2134(02)00350-2

[30] Dong, M., Anda, R.F., Dube, S.R., Giles, W.H. and Felitti, V.J. (2003) The Relationship of Exposure to Childhood Sexual Abuse to Other Forms of Abuse, Neglect, and Household Dysfunction during Childhood. Child Abuse \& Neglect, 27, 625-639. https://doi.org/10.1016/S0145-2134(03)00105-4

[31] Lansford, J.E., Dodge, K.A., Pettit, G.S., Bates, J.E., Crozier, J. and Kaplow, J. (2002) A 12-Year Prospective Study of the Long-Term Effects of Early Child Physical Maltreatment on Psychological, Behavioral, and Academic Problems in Adolescence. Archives of Pediatrics and Adolescent Medicine, 156, 824-830. https://doi.org/10.1001/archpedi.156.8.824

[32] Lowell, A., Renk, K. and Adgate, A.H. (2014) The Role of Attachment in the Relationship between Child Maltreatment and Later Emotional and Behavioral Functioning. Child Abuse \& Neglect, 38, 1436-1449.

https://doi.org/10.1016/j.chiabu.2014.02.006

[33] United Nations Children's Fund (2012) Child Maltreatment: Prevalence, Incidence 
and Consequences in the East Asia and Pacific Region: A Systematic Review of Research.

[34] Fry, D., McCoy, A. and Swales, D. (2012) The Consequences of Maltreatment on Children's Lives: A Systematic Review of Data from the East Asia and Pacific Region. Trauma. Violence Abuse, 13, 209-233. https://doi.org/10.1177/1524838012455873

[35] Gilbert, R., Widom, C.S., Browne, K., Fergusson, D., Webb, E. and Janson, S. (2009) Burden and Consequences of Child Maltreatment in High-Income Countries. The Lancet, 373, 68-81. https://doi.org/10.1016/S0140-6736(08)61706-7

[36] Heim, C. and Nemeroff, C.B. (2001) The Role of Childhood Trauma in the Neurobiology of Mood and Anxiety Disorders: Preclinical and Clinical Studies. Biological Psychiatry, 49, 1023-1039. https://doi.org/10.1016/S0006-3223(01)01157-X

[37] Spertus, I.L., Yehuda, R., Wong, C.M., Halligan, S. and Seremetis, S.V. (2003) Childhood Emotional Abuse and Neglect as Predictors of Psychological and Physical Symptoms in Women Presenting to a Primary Care Practice. Child Abuse \& Neglect, 27, 1247-1258. https://doi.org/10.1016/j.chiabu.2003.05.001
Abbreviations
$\mathrm{ACE}=$ Adverse Childhood Experience
K10 $=$ Kessler Psychological Distress Scale
$\mathrm{OR}=$ Odds Ratio
SPSS $=$ Statistical Package for Social Sciences
USA $=$ United States of America
WHO $=$ World Health Organization 